\title{
LA DIPLOMACIA CULTURAL ALEMANA Y EL CINE DE PROPAGANDA NAZI EN LA ARGENTINA EN EL PERÍODO PREVIO A LA SEGUNDA GUERRA MUNDIAL
}

\author{
German Cultural Diplomacy and Nazi \\ Propaganda Cinema in Argentina prior to the II World War \\ MARÍA VALERIA GALVÁN ${ }^{\mathrm{a}}$ \\ CONICET - Universidad Nacional de San Martín \\ MARINA MOGUILlansKy ${ }^{\mathrm{b}}$ \\ CONICET - Universidad Nacional de San Martín \\ DOI: $10.15366 /$ secuencias2020.52.004
}

\begin{abstract}
RESUMEN
En este trabajo abordamos la articulación entre política, diplomacia cultural y cine en relación con los vínculos de la Argentina con la Alemania nazi en el período previo a la declaración de la Segunda Guerra Mundial. En primer lugar, caracterizamos las relaciones culturales entre Alemania y Argentina, atendiendo al despliegue de la diplomacia cultural alemana en el país y a los vínculos que estableció con la comunidad local, en particular en el ámbito del cine. En la segunda sección, describimos la circulación de cine alemán en Buenos Aires en el período que va desde 1935 hasta 1939, con el estallido de la guerra. Allí, analizamos el rol de las principales distribuidoras de cine alemán, sus contactos con las productoras alemanas y con cierto circuito de salas. Nos ocupamos especialmente de los títulos que fueron posteriormente censurados por considerarse «propaganda nazi» en cuanto a su permanencia en cartelera y la recepción crítica.
\end{abstract}

Palabras clave: nazismo, diplomacia cultural, cine de la UFA, Argentina.

\begin{abstract}
In this work, we address the articulation between politics, cultural diplomacy and cinema, in relation to Argentina's ties with Nazi Germany in the period prior to the declaration of World War II. First, we characterize the cultural relations between Germany and Argentina, taking into account the deployment of German cultural diplomacy in the country and the links it established with the local community, particularly in the field of cinema. In the second section, we describe the circulation of German cinema in Buenos Aires in the period from 1935 to 1939, with the outbreak of war. There, we analyzed the role of the main German cinema distributors, their contacts with German producers and with a certain theater circuit. We deal especially with the titles that were later censored for being considered «nazi propaganda» in terms of their permanence in theaters and critical reception.
\end{abstract}

Keywords: Nazism, Cultural Diplomacy, UFA Films, Argentina.

[a] María VAleRIa Galvín es profesora e investigadora adjunta del CONICET con lugar de trabajo en el Instituto de Investigaciones Políticas, en la Universidad Nacional de San Martin. Tiene varias publicaciones académicas sobre la historia cultural e intelectual del Nacionalismo, la Guerra Fría Cultural y el Posperonismo. Es autora de El Nacionalismo de derecha en la Argentina posperonista. El semanario Azul y Blanco (1956-1969) (Rosario, Prohistoria Ediciones, 2013), coeditó junto a Florencia Osuna el libro Política y cultura durante el «Onganiato». Nuevas perspectivas para la investigación de la presidencia de Juan Carlos Onganía (1966-1970) (Rosario, Prohistoria, 2014) y co-coordinó también con Osuna el libro La Revolución Libertadora en el marco de la Guerra Fría (Rosario, Prohistoria, 2018).

[b] Marina Moguillansky es profesora e investigadora Adjunta del CONICET, con lugar de trabajo en la Escuela de Altos Estudios Sociales de la Universidad Nacional de San Martín, y profesora invitada de la Universidade Federal da Paraíba (UFPB). Publicó Cines del Sur. La integración cinematográfica entre los paises del Mercosur (Buenos Aires, Imago Mundi, 2016). Coordina el Núcleo de Estudios en Cultura y Comunicación en IDAES-UNSAM. mmoguillansky@gmail.com. 


\section{Introducción $^{1}$}

La población de Buenos Aires, una de las principales capitales culturales de América Latina, ha cultivado a lo largo del siglo XX una asistencia regular a las salas de cine, a través de las cuales pretendía no sólo distenderse, sino — sobre todo en la primera mitad de siglo - informarse de los acontecimientos mundiales, a través de las proyecciones de noticiarios cinematográficos, previos a los filmes de ficción. En este sentido, la preocupación de Alemania por exportar sus producciones cinematográficas a la capital sudamericana halló un terreno fértil en la Buenos Aires de los años $30^{2}$. Si bien el impacto de la Segunda Guerra Mundial y en particular del nazismo en la sociedad argentina han sido analizados por la historiografía en relación con las comunidades de inmigrantes, a la prensa gráfica y a otros actores específicos del escenario local, como militares, intelectuales nacionalistas ${ }^{3}$, no se ha abordado aún la repercusión local de una de las agencias emergentes de difusión propagandística de la época: el cine.

En este trabajo nos proponemos explorar un aspecto de la diplomacia cultural de la Alemania nazi en la Argentina a través del análisis de la circulación de cine de propaganda nazi en el país. En efecto, el cine alemán tuvo una amplia llegada a la Argentina en este período y colaboró con la difusión del proyecto político, económico y cultural nazi. Sin embargo, no resulta claro en qué sentido puede hablarse de «propaganda política» ni tampoco hay consenso acerca de cuáles filmes exhibían una ideología nazi: para algunos críticos, todo el cine alemán de la época estaba alineado con los principios del nacionalsocialismo — es la óptica, por ejemplo, de Eric Rentschler ${ }^{4}$ - , mientras que otros análisis destacan la heterogeneidad de las películas y los rasgos populares de este cine, como propone Sabine Hake ${ }^{5}$. En este trabajo, como primera aproximación, utilizamos las listas de filmes nazis «reservados» o prohibidos, elaboradas por una comisión militar de los Aliados en la década de 1950 y posteriormente por la Fundación Friedrich Wilhelm Murnau, para rastrear sus estrenos en Buenos Aires, las condiciones de distribución y exhibición, y las críticas que recibieron por parte de la prensa diaria y especializada.

A partir de este relevamiento pudimos observar que, si bien el mercado cinematográfico de la Buenos Aires de los años 30 no fue una excepción en términos de apreciación de la calidad artística del cine germano-parlante, tuvo la particularidad de haber propiciado un contexto que favoreció el ingreso de este cine, un cine que pronto fue instrumentalizado como parte del aparato propagandístico del III Reich, y que, como tal, contribuyó a la divulgación del imaginario nacionalsocialista en suelo sudamericano.

Así, en la primera sección, presentamos un panorama del nazismo en la cultura porteña de la época de preguerra y describimos el rol del cine como parte de la diplomacia cultural alemana en la Argentina y, en este sentido, hacemos un breve recorrido por la historiografía que se abocó a su estudio desde diferentes aristas del fenómeno, durante el periodo abordado. En la segunda sección, analizamos específicamente la circulación de cine de propaganda nazi en las pantallas de Buenos Aires entre 1935 y 1942, a través de los casos concretos que encontramos. Por último, en las conclusiones recapitulamos las particularidades del contexto político local que beneficiaron la circulación de la filmografía nazi y sintetizamos los hallazgos de nuestra investigación, que, a su vez, abre nuevos interrogantes para futuras indagaciones.
[1] N. del E.: Los títulos de las películas que se citan en castellano a lo largo del texto corresponden a los de estreno en Argentina.

[2] Emeterio Díez Puertas, Cine español y geopolítica fascista. España y sus relaciones cinematográficas con la Argentina (19391943) (Madrid, Síntesis, 2019).

[3] Germán Friedmann, Alemanes antinazis en la Argentina (Buenos Aires, Siglo XXI, 2010); Andrés Bisso, Acción Argentina: un antifascismo nacional en tiempos de guerra mundial (Buenos Aires, Prometeo, 2005); Christian Buchrucker, Nacionalismo y Peronismo (1930-1955). La Argentina en la crisis ideológica mundial (Villa Ballester, Sudamericana, 1999); Tulio Halperín Donghi, La Argentina y la tormenta del mundo (Buenos Aires, Siglo XXI, 2003); María Inés Tato, «El ejemplo alemán. La prensa nacionalista y el Tercer Reich» (Revista Escuela de Historia 1.6, 2007); María Inés Tato y Luis Alberto Romero, «La prensa periódica argentina y el régimen nazi», en I. Klich (comp.) Sobre nazis y nazismo en la cultura argentina (Gaithesburg, Hispamerica, 2002); Federico Finchelstein, Fascismo, liturgia e imaginario: el mito del General Uriburu y la Argentina nacionalista (Buenos Aires, Fondo de Cultura Económica, 2002); Ignacio Klich «La contratación de nazis y colaboracionistas por la Fuerza Aérea Argentina» (Ciclos en la historia, la economía y la sociedad, Año X, Vol. X, n. ${ }^{\circ} 19$, 2000), pp. 177-216.

[4] Eric Rentschler, The Ministry of Illusion. Nazi Cinema and its Afterlife (Boston, Harvard University Press, 1996).

[5] Sabine Hake, Popular Cinema of the Third Reich (Austin, University of Texas Press, 2001).). 


\section{La diplomacia cultural alemana en la Argentina de preguerra}

La diplomacia cultural del Estado nacional-socialista tuvo una destacada actuación en la promoción de las transferencias culturales de la Alemania nazi hacia la Argentina a partir del atractivo y popular cine de la compañía cinematográfica Universum Film-Aktiengesellschaft (UFA). Si bien la industria cinematográfica alemana había tenido un desarrollo más lento que la norteamericana, alcanzó un pico de crecimiento y esplendor en los años de la Primera Guerra Mundial. Así, en 1917 se fundó la UFA, con el fin de compensar la merma de filmes importados a Alemania. Esta iniciativa originalmente privada integraría todas las productoras existentes (incluyendo las iniciativas previas del ejército alemán $)^{6}$.

Desde el inicio, la industria cinematográfica alemana se había caracterizado por la concentración monopólica de la producción, la relación estrecha con el Estado, la tradición propagandística y el innovador manejo de los medios de comunicación masiva. Pero estas tendencias se vieron reforzadas a partir de marzo de 1933, cuando Josef Goebbels se hizo cargo del Ministerio de Instrucción Popular y Propaganda. En 1934 se creó una cámara de la industria cinematográfica y se promulgó la censura. Así, en los años subsiguientes, Goebbels logró el control completo de la industria. Desde ese momento, su objetivo fue que los filmes alemanes resultaran un vehículo para el entretenimiento y que al mismo tiempo difundieran los ideales del régimen, ya sea de forma explícita, como exaltación del nacionalismo alemán —en detrimento de un otro demonizado - o bien implícitamente a través de películas románticas, comedias y documentales.

Paralelamente, se pretendía producir un cine de calidad para lograr el éxito en los mercados internacionales y competir con Hollywood. En este aspecto no fue tan exitosa la estrategia ya que las ventas internacionales sufrieron pronto una estrepitosa caída, acompañada por el exilio de las grandes estrellas de prestigio internacional (muchas de ellas perseguidas por su origen judío), lo cual fue en detrimento de la calidad narrativa y artística del cine alemán. Esto se agravó con un incremento de costos en la producción fílmica.

En 1936, la inestabilidad financiera de las mayores compañías cinematográficas UFA y Tobis (Tonbild-Syndikat Aktien-Gesellschaft, compañía alemana con capitales holandeses), repercutió en la construcción del monopolio estatal, que fue avanzando sobre Tobis (a través de la subsidiaria Cautio). En 1937, Terra Film Aktien-Gesellschaft (una subsidiaria suiza de la UFA) fue amalgamada con Tobis Rota para formar una nueva compañía, Terrakunst GmbH. Poco tiempo después, Cautio compró Bavaria Film AG, que se renombró como Bavaria Filmkunst GmbH. Al mismo tiempo, Goebbels anunció la creación de la Deutsche Filmakademie, con el

[6] Karsten Witte, «Film im Nationalsozialismus», en Wolfgang Jacobson, Welten Kees and Hans Helmut Prinzler, (eds.), Geschichte des deutschen Films (Stuttgart, Springer-Verlag, 2016).

[7] R. Vande Winkel y D.Welch, Cinema and the Swastika: The International Expansion of Third Reich Cinema (Basingstoke, Palgrave Macmillan, 2007). objetivo de formar nuevos técnicos y artistas del Estado nacional socialista. En 1938, con el Anschluss de Austria, la subsidiaria Cautio absorbió la compañía Wien Film GmbH y lo mismo pasó con Prag-Film, poco después. La concentración y los recursos económicos, técnicos y artísticos con los que llegó a contar la cinematografía alemana en 1939 fueron inigualables respecto a cualquier otra cinematografía europea y comparable con Hollywood ${ }^{7}$.

El cine de la UFA era una carta valiosa dentro de las estrategias diplomáticas que el gobierno alemán podía desplegar en América Latina. Particularmente en Argentina, su peso en las listas anuales de estrenos da cuenta de la inversión que la política exterior alemana hizo en este sentido en el país sudamericano durante la década de 
los años treinta. Así, aun cuando el cine germano-parlante llegaba con regularidad a la Argentina antes de la intervención norteamericana para cercenar este flujo, no toda esta filmografía exhibida en las salas locales era nazi. Es decir, no todas las películas estrenadas en Argentina en idioma alemán, durante el gobierno nazi, fueron filmes de propaganda. Para identificar este tipo particular de cinematografía, cruzamos los documentos de estrenos alemanes en el periodo 1933-1939 con algunas listas de películas alemanas que fueron consideradas contemporáneamente de ideología peligrosa y siguen prohibidas para la exhibición hasta la actualidad.

Una primera lista fue elaborada por la Comisión de Censura militar de los Aliados, en 1951, conteniendo alrededor de $200 \mathrm{films}^{8}$; a partir de esa lista, se elaboró luego otra más selectiva con 118 títulos $^{9}$. Posteriormente, la Fundación Friedrich Wilhelm Murnau de Alemania, que posee los derechos de exhibición de casi todas esas películas y su guarda institucional, elaboró una lista más limitada, con 44 títulos de películas consideradas de carácter «reservado» por sus contenidos racistas, por glorificar la guerra o por incitar a la violencia ${ }^{10}$. Actualmente, estos filmes sólo pueden ser exhibidos con la autorización de la fundación y bajo las condiciones que ésta defina, que por lo general suelen consistir en que se incluya una contextualización histórica y se cuente con un espacio para la discusión guiada por expertos ${ }^{11}$.

De las películas alemanas que aparecen en alguna de dichas listas, un total de 15 títulos se estrenaron comercialmente en la Argentina entre 1935 y 1942, y algunos de ellos con gran éxito. De éstos, los de mayor impacto en el mercado cinematográfico porteño permanecieron entre diez y veinte semanas en cartel, que para la época era un tiempo muy considerable y superior al promedio de permanencia que lograban otros estrenos. Sin embargo, como veremos, esta relación cambiaría a partir de 1939, cuando comienzan a mermar los estrenos de filmes alemanes, debido a la ruptura de relaciones entre algunos actores del mundo del cine en Argentina y sus contrapartes alemanas, y también como respuesta a las presiones ejercidas por el Departamento de Estado norteamericano en el mercado cinematográfico local.

Hasta la actualidad, las especificidades de la diplomacia cultural alemana en la Argentina durante los años de la preguerra no han sido trabajadas en el terreno cinematográfico. Encontramos una amplia bibliografía acerca de la actuación de la diplomacia cultural nazi en Argentina en otros espacios culturales, cuyos principales hallazgos sintetizaremos aquí. La actuación alemana en la prensa periódica masiva de la Argentina fue analizada por María Inés Tato y Luis Alberto Romero, observando que la mayor parte de los periódicos de la época (con la excepción del diario Crítica) consideró al nazismo, en un comienzo, como un mero resultado exótico de la posguerra europea ${ }^{12}$. Aun cuando sectores importantes del campo político de los años treinta, como los nacionalistas, los católicos o los comunistas, entre otros, representan una excepción a esto, la mayoría de la ciudadanía argentina se caracterizó por la desmovilización política ${ }^{13}$. Precisamente, la década de los años treinta se inicia en la Argentina con el golpe de Estado del general José Uriburu que clausura la participación política. De corte nacionalista, corporativista y con simpatías fascistas, la dictadura de Uriburu fue cuestionada internamente por su inoperancia y consecuentemente desarticulada en favor de un gobierno fraudulento, de la mano de una facción militar opositora que se asoció con sectores civiles, opositores al gobierno democrático de Hipólito Yrigoyen, anteriormente depuesto. Así, de la mano del general Agustín Justo, se formó un bloque interpartidario (conocido como la Concordancia) que dominó el escenario político a través del fraude a lo largo de la década hasta 1943,
[8] Virginio Ilari, «Verbotene Filme. I Kriegsfilme del Terzo Reich» (Conference Paper, mayo de 2015, p. 2).

[9] John F. Kelson y R. M. Kenneth Short (eds.), Catalogue of Forbidden German Feature and Short Film Productions: Held in Zonal Film Archives of Film Section, Information Services Division, Control Commission for Germany. (Trowbridge, Flicks Books, 1996).

[10] La versión actual de la lista puede consultarse aquí: https:// www.murnau-stiftung.de/movie_search?genre= 22 .

[11] Joseph Garncarz, Begeisterte Zuschauer: Die Macht des Kinopublikums in der NS-Diktatur (Köln, Halem, 2020).

[12] María Inés Tato y Luis Alberto Romero, «La prensa periódica argentina y el régimen nazi», pp. 157-165.

[13] Leandro Losada (comp.). Política y vida pública. Argentina (1930-1943) (Buenos Aires, Imago Mundi, 2017). 
[14] Luciano de Privitellio, «La política bajo el signo de la crisis», en Alejandro Cattaruzza, Crisis económica, avance del Estado e incertidumbre política 19301943: nueva historia argentina. Vol. 7 (Buenos Aires, Sudamericana, 2014).

[15] Christian Buchrucker, $\mathrm{Na}$ cionalismo y Peronismo, p. 190.

[16] Olga Echeverrría, «La derecha nacionalista. Decepciones políticas e influjos culturales», en Leandro Losada (comp.), Política y vida pública. Argentina (19301943) (Buenos Aires, Imago Mundi, 2017), pp. 61-64.

[17] Tulio Halperín Donghi, La Argentina y la tormenta del mundo, pp. 23-48; María Inés Tato, «El ejemplo alemán. La prensa nacionalista y el Tercer Reich», pp. 33-57; Christian Buchrucker, Nacionalismo y Peronismo, p. 188.

[18] Ricardo Pasolini, Los marxistas liberales. Antifascismo y cultura comunista en la Argentina del siglo XX (Buenos Aires, Sudamericana, 2013); Ricardo Passolini, «Comunismo y cultura política comunista: el momento antifascista», en Leandro Losada (comp.), Política y vida pública. Argentina (1930-1943), pp. 69-86; Ricardo Martínez Mazzola, «El Partido Socialista en los años treinta», en Leandro Losada (comp.), Política y vida pública. Argentina (1930-1943) pp. 88-105; Andrés Bisso, Acción Argentina; José Zanca, Cristianos antifascistas. Conflictos en la cultura católica argentina (Buenos Aires, Siglo XXI, 2013).

[19] María Inés Tato y Luis A1berto Romero, «La prensa periódica argentina y el régimen nazi», pp. 157-165.

[20] Tulio Halperín Donghi, La Argentina y la tormenta del mundo, pp. 23-48; María Inés Tato, «El ejemplo alemán», pp. 33-57. cuando hubo un nuevo golpe ${ }^{14}$. Los sucesivos gobiernos de la Concordancia fueron considerados por la diplomacia alemana como un marco propicio para la divulgación propagandística ${ }^{15}$.

Pero más allá de las facilidades que la política partidaria local pueda haber proporcionado a la propaganda nazi, la derecha nacionalista argentina se prestó a la propagación de un ideario con muchos puntos en común con el nazismo (nacionalismo, antisemitismo, corporativismo, exaltación del líder, entre otros). En efecto, el nacionalismo local — asociado al elenco golpista del 30 - cobró mayor impulso en este período y desde sus organizaciones políticas y publicaciones periódicas fomentó un radicalismo extremo que exultaba de admiración por los regímenes fascistas europeos, los cuales parecían ofrecer la solución a los problemas estructurales de la democracia liberal. A través de los medios de los que disponían, sin embargo, alcanzaron mayor repercusión en los imaginarios sociales contemporáneos que en la arena política ${ }^{16}$.

Es que, en efecto, la opinión pública argentina sólo se compenetró en la política internacional a partir de una mirada cruzada por los problemas políticos internos. En este sentido, la lectura de la página internacional siempre se hacía en comparación con posibles equivalentes locales. Así, por ejemplo, algunos sectores de la derecha doméstica vieron a los fascismos no sólo como una solución a las falencias de la democracia liberal, sino también como una posible valla de contención frente al comunismo. De este modo, a través de un anticomunismo más amplio que comenzó a constituirse como un aglutinante de las derechas en general, el nazismo pasó a ser admirado por un sector de relevancia del espectro político argentino ${ }^{17}$. Como contracara a ello, también el antifascismo local entendido como antitotalitarismo, ganaría mayor preponderancia en el nuevo contexto prebélico y se solaparía a la vez con las sensibilidades políticas locales ${ }^{18}$.

En síntesis, en el marco de un convulsionado contexto internacional de entreguerras marcado por el peligro comunista y el ascenso de los fascismos europeos en general, la sociedad argentina comenzó a verse movilizada por esta agenda internacional pero siempre sin correr la mirada de las tensiones propias de la cultura política local. Así, en ese clima, el nazismo suscitó curiosidad en la opinión pública argentina por el estilo político novedoso que representaba y esto logró amalgamarse, a su vez, con una tónica anticomunista generalizada, que contraponía el «peligro rojo» al nazismo. En dicho sentido, la «prensa seria» tuvo puntos de contacto con la prensa local de derecha abiertamente antisemita, que era subsidiada por la embajada alemana ${ }^{19}$.

La prensa nacionalista y antisemita argentina fue un espacio de resonancia para la propaganda nazi en el país. Las publicaciones periódicas locales directamente subsidiadas por el Estado alemán fueron Bandera argentina (de una tirada de mil ejemplares), Crisol (de una tirada de 4 mil ejemplares) y El pampero (de una tirada de entre 15 y 80 mil ejemplares). Este tipo de prensa gráfica presentaba al nazismo como el modelo de unidad nacional a seguir, bajo las banderas del antiliberalismo y el antisemitismo. Posteriormente, el desencadenamiento del conflicto motivó la moderación de las posturas y la adscripción a uno de los bandos en los que se había dividido la sociedad. Así, tanto los medios gráficos como el campo intelectual en sí terminaron por dividirse entre aliadófilos y neutralistas ${ }^{20}$.

La diplomacia alemana en el país, si bien buscaba en primer lugar ganar una posición comercial para Alemania en la relación con la Argentina, siempre tuvo también como objetivo obtener el favor de la opinión pública latinoamericana y, para 
ello, vio a la radio, la prensa gráfica y el cine como medios seguros y eficaces para lograr sus objetivos de cooptación ${ }^{21}$. En cuanto al impacto de la propaganda nazi en la Argentina, logró una gravitación importante sobre la comunidad alemana local22, aunque también hubo excepciones: se desarrollaron en Buenos Aires espacios opositores al régimen, como la asociación Das andere Deutschland, el colegio Pestalozzi, el Cangallo Schule, que fueron verdaderos resguardos comunitarios, frente a un mayoritario apoyo del resto de los inmigrantes alemanes en la Argentina. ${ }^{23}$

En este sentido, tanto en los actos de violencia contra trabajadores de periódicos anti-fascistas, como en el saludo nazi obligatorio de las escuelas alemanas, en los masivos actos organizados en el salón de espectáculos deportivos y culturales más importante de la escena porteña, el Luna Park, en las actividades de propaganda de los pastores alemanes en las escuelas rurales o en los materiales pedagógicos oficiales con contenidos racistas, se observa la intervención del Estado alemán para impulsar la divulgación del imaginario nazi. Esto cobra sentido en el marco del proceso de Gleichschaltung («uniformación o alineación») de las organizaciones culturales, sociales, deportivas y religiosas de la colectividad alemana en el mundo, por el cual Alemania buscó extender su influencia en los países receptores de población germana, con el fin de recuperar para sí las mentalidades de los alemanes en el extranjero. En el caso de países como Argentina, sin embargo, ello fue visto como un ataque directo a las políticas del Estado local ${ }^{24}$.

Uno de los principales agentes locales para articular la estrategia de la propaganda alemana fue el Landesgruppe Argentinien der NSDAP. Su objetivo era lograr que quienes habían emigrado en el pasado de Alemania y sus descendientes se transformasen en difusores de las ideas nacionalsocialistas. Esto impugnaba abiertamente el proyecto inmigratorio del Estado argentino, por lo que éste se vio obligado, en 1938, a tomar medidas más directas contra las escuelas alemanas pronazis. Aun cuando el Landesgruppe nunca dejó de ser minoritario, incluso dentro de la comunidad misma de inmigrantes alemanes, logró incrementar la movilización argentina en favor del nazismo ${ }^{25}$, posiblemente porque contaba con conexiones importantes en las empresas

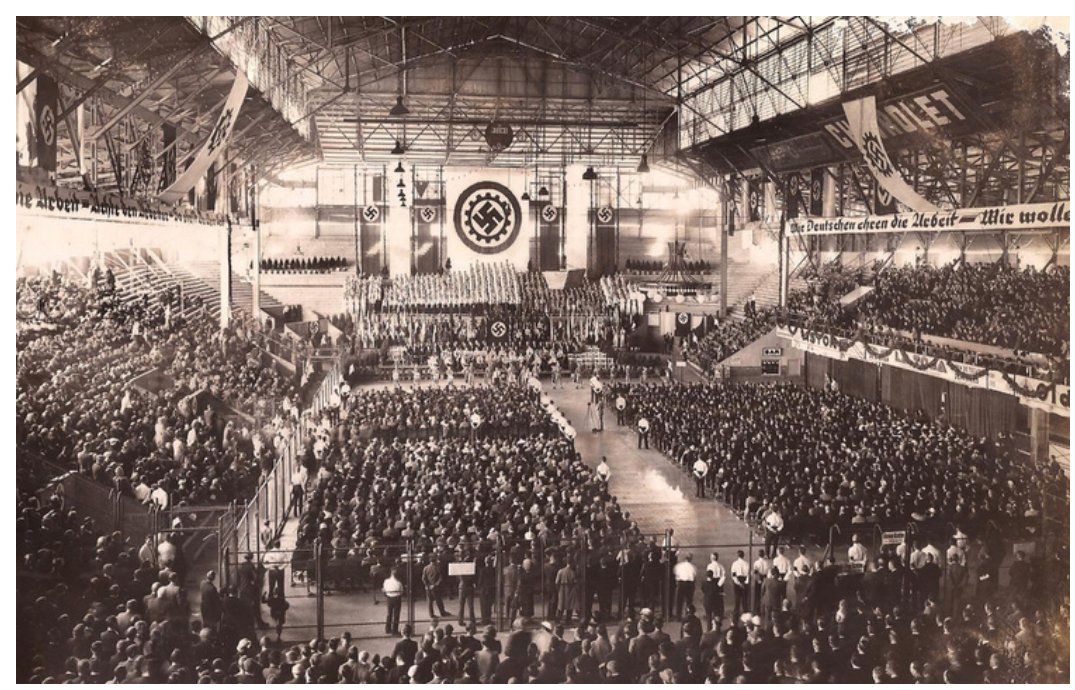

Una multitud reunida en el acto de celebración por el Anschluss, realizado el 10 de abril de 1938 en el Luna Park, Buenos Aires.
[21] Christian Buchrucker, $N a$ cionalismo y Peronismo, pp. 184-205.

[22] Germán Friedmann, «E1 discurso nacionalsocialista en la Argentina frente a la "infiltración nazi”») (Prohistoria, vol. 32, Prohistoria Ediciones, 2019).

[23] Germán Friedmann. Alemanes antinazis en la Argentina.

[24] Christian Buchrucker, $\mathrm{Na}$ cionalismo y Peronismo, p. 185.

[25] Germán Friedmann, «E1 discurso nacionalsocialista en la Argentina». 
[26] Mario Rapoport, Andrés Musacchio, y Christel Converse, «Las inversiones alemanas en Argentina entre 1933 y 1945: ¿base material de la expansión de los nazis?» (Iberoamericana, VI, 21, 2006), pp. 45-69; Olga Echeverria, «Las derechas de Argentina y Uruguay en tiempos de nazi fascismos: radicalización, redefiniciones e influencias» (Oficina do historiador, 9, 1, 6-2016), pp. 151-170. Disponible en: <http:// hdl.handle.net/11336/26643>.

[27] Ursula Prutsch, Creating Good Neighbors? Die Kulturund Wirtschaftspolitik der USA in Lateinamerika, 1940-1946 (Stuttgart, Steiner, 2008).

[28] Ursula Prutsch, Creating Good Neighbors? Die Kultur- und Wirtschaftspolitik der USA in Lateinamerika, 1940-1946.

[29] Andrés Bisso, Acción Argentina: un antifascismo nacional. y el Estado alemanes. Uno de sus principales triunfos fue el acto del 10 de abril de 1938 en el Luna Park para celebrar el Anschluss austríaco y que, a pesar de suscitar una fuerte resistencia en la opinión pública argentina y en parte de su clase política, se celebró con quince mil asistentes.

Casi inmediatamente se prohibieron las manifestaciones de simbología nazi en las escuelas, se proscribió el Landesgruppe y asociados (mayo de 1939) y se creó una Comisión Investigadora de Actividades Antiargentinas, que presentó informes anuales sobre las actividades nazis en el país entre 1941 y $1943^{26}$. Sin embargo, el principal límite a la diplomacia cultural alemana en Argentina provino del exterior, cuando en julio de 1941 se fundó la Asociación de Difusión Interamericana (ADI), vinculada al FBI y financiada por la Oficina de Asuntos Interamericanos (OIAA), que se ocuparía de interferir en la misión de los periódicos locales subvencionados por los países del Eje. La ADI produciría contenidos informativos y culturales, con su propia agencia de noticias y fotos, una agencia de información de comercio exterior, una sección de Publicidad, Radio, Film y Cultos, desde las cuales buscaría articular con los medios locales. Desde diciembre de 1942, tuvo su propia sección fílmica, y desde marzo de 1944, comenzó a registrar y denunciar todos los filmes importados desde los países del Eje y las reacciones del público, mientras brindaba también datos acerca de las relaciones de poder de la industria local con el Eje ${ }^{27}$.

En este marco, la importación de cine alemán tenía un rol destacado dentro del abanico de acciones propagandísticas. En 1943, la Comisión de Actividades Antiargentinas descubrió vínculos entre empresas de los países del Eje y la Argentina, en varios casos relacionados con el mundo del cine. Al respecto, la ADI registró que hasta la década del 40 los filmes europeos siempre fueron bien recibidos entre el público argentino: en el país se estrenaba un promedio de veinte filmes alemanes por año hasta 1942. Frente a esta situación y al registro de actividades propagandísticas bélicas, la OIAA decidió aplicar las listas negras y el boicot a salas, distribuidoras y periódicos que favorecieran la propaganda nazi. A su vez, como respuesta a las listas negras, Alemania desarrolló diversas estrategias para recuperar su lugar en el mercado cinematográfico argentino ${ }^{28}$.

Luego del golpe militar de 1943, el general Ramírez ejerció control político y financiero de los medios masivos y de la producción intelectual. De este modo, se concentró sobre todo en la radio, como el principal medio de mayor alcance. La censura se aplicó a las noticias y a la música por igual. En este contexto, se prohibieron periódicos judíos y publicaciones y filmes comunistas y se censuraban manifestaciones antialemanas. Del mismo modo, organizaciones pro-aliadas como Acción Argentina y Junta de la Victoria también sufrieron persecuciones y se vieron afectadas por las redes de la censura ${ }^{29}$.

Sin embargo, si bien las afinidades políticas del gobierno argentino parecían plasmar el gusto germanófilo que el público porteño había mostrado antes de la intervención de la OIAA, esto no responde a la pregunta acerca de las causas de esta preferencia de los espectadores locales por el cine nazi. Efectivamente, el consumidor de cine promedio en la Buenos Aires de esos años, si bien no era abiertamente opositor en su gran mayoría al nazismo, tampoco hallaba en sus defensores explícitos referencias importantes a seguir. De hecho, ni los periódicos, ni los intelectuales nacionalistas argentinos germanófilos tuvieron - como dijimos- un peso importante en la política local y, si bien se destacaron más en el campo de la cultura, tampoco ejercieron desde ese lugar una influencia generalizada ni duradera. 
Una posible clave interpretativa para abordar el éxito relativo del cine nazi en Argentina antes de la guerra deba fijarse en los tópicos de las películas que llegaban a Sudamérica. En ese sentido, aquello que el nazismo parecía despertar en la opinión pública mayoritaria tenía tal vez origen en la curiosidad por un fenómeno político con un estilo novedoso, una inquietud político-intelectual de la clase media porteña, que la definía en relación a sus consumos culturales desde las primeras décadas del siglo $\mathrm{XX}^{30}$. Por otro lado, el cine alemán de la década del 30 era una de las principales cinematografías mundiales de la época. En relación con ello, como veremos en el próximo apartado, la circulación de las películas nazis en Argentina — y en otros países de América Latina - fue indudablemente intensa en los años previos a la guerra y despertó el interés de parte de los espectadores hasta que interfirió en este proceso la diplomacia cultural norteamericana.

\section{El cine alemán y la propaganda nazi en Buenos Aires}

Durante la década de 1930, la Argentina contaba con alrededor de 1600 salas de cine — situándose así en el primer lugar en términos de la cantidad de salas en América Latina $^{31}$ — de las cuales casi 200 estaban ubicadas en la ciudad de Buenos Aires ${ }^{32}$. En este período, las pantallas de cine porteñas tenían una presencia mayoritaria de cine hablado en inglés; específicamente, alrededor de un $75 \%$ de los estrenos de películas provenía de los Estados Unidos, debido a que Hollywood ya era dominante en ese momento. Sin embargo, las películas de origen alemán tenían - como dijimosuna presencia considerable en las pantallas de la Argentina, ligeramente superior a la presencia de los cines de otros países europeos.

El principal importador de cine europeo en Argentina había sido, desde la década de 1920, Max Glucksmann, un inmigrante judío de origen austríaco que tuvo un contrato de exclusividad con la francesa Pathé y que también tenía contactos con Alemania. Hacia la década de 1930 la distribuidora más importante de cine alemán será la empresa Cinematográfica Terra, bajo la dirección de Adolfo Zicovich-Wilson, pues contó con el monopolio de los títulos de UFA, hasta fines del año $1938^{33}$ y distribuía también la mayor parte de los títulos de Tobis, otra productora alemana. Los estrenos de películas distribuidas por Terra fueron en su mayoría en el cine Monumental, ubicado en el centro de la ciudad de Buenos Aires, una de sus salas más importantes; y con menor frecuencia, se asoció para exhibir sus películas con las salas del cine Ambassador o con el Gran Rex, también salas céntricas de la ciudad. Entre 1935 y 1938 trajo a la Argentina un total de 36 películas alemanas, de las cuales 8 fueron títulos posteriormente censurados.

En segundo lugar, se encuentra la compañía Cinematográfica Sud América, fundada por Atilio Liberti, que se dedicaba desde comienzos de siglo a la distribución de películas europeas y que en este período tuvo el contrato de distribución de las películas de la compañía alemana Terra Film AG, que fuera la productora, entre otras, de las películas dirigidas por Herbert Selpin y también las de Paul Heinz. La Compañía Sud América estrenaba las películas en las salas de los cines Renacimiento, Paramount y ocasionalmente en el cine Monumental. Entre 1936 y 1937 importó nueve películas alemanas, de las cuales 3 resultarían más tarde prohibidas.

Por último, con menor participación, encontramos a Julio Joly, un distribuidor independiente que contaba con el contrato de exclusividad de Gaumont — una importante empresa francesa- y que ocasionalmente traía a la Argentina también películas
[30] L. Vainikoff, entrevistado por Valeria Galvan y Michal Zourek (Buenos Aires, junio 2016).

[31] Si tomamos el año 1933 como referencia, la Argentina superaba a Brasil, que contaba entonces con 1100 salas y a México, que contaba con 700 salas, según consta en Paulo Antonio Paranaguá, «América Latina busca su imagen», Historia General del Cine (Madrid, Cátedra, 1996), p. 208.

[32] Clara Kriger, «Gestión estatal en el ámbito de la cinematografía argentina (1933-1943)» (Anuario del Centro de Estudios Históricos Prof. Carlos S. A. Segreti, año 10, n. $\left.{ }^{\circ} 10,2010\right)$.

[33] Wolfgang Fuhrmann, «Sueños en blanco y negro: la expansión de la UFA en Brasil y América Latina», incluido en este monográfico (Secuencias. Revista de Historia del Cine, $\mathrm{n}^{ }$ 52, 2020), pp. 57-76 
alemanas, en particular las producidas por Boston Films. Solía estrenar las películas en el cine Suipacha o en el cine Ópera. Entre 1935 y 1938 trajo cinco películas alemanas a Buenos Aires, una de las cuales fue más tarde incluida en la lista de películas «reservadas». Otras distribuidoras de cine alemán en el período fueron Andes Film, British Alianza e Inca Film.

Entre 1935 y 1939, se estrenó un promedio de veinte películas alemanas por año en los cines de la ciudad de Buenos Aires. Esta cifra representaba, en la época, alrededor del $5 \%$ de los estrenos totales, de modo que podemos afirmar que se estrenaron más películas alemanas que italianas o francesas, ya que estas últimas suponían un 3 $\%$ de los estrenos en cada caso. De ese conjunto de películas alemanas, una minoría puede considerarse como propaganda nazi, de acuerdo a las listas de películas «reservadas» que mencionamos previamente. Para el período examinado, encontramos registros de la exhibición en Buenos Aires de un total de 15 títulos de películas reservadas, cuya distribución se observa en la siguiente tabla.

\begin{tabular}{|c|c|c|c|}
\hline Año & Título, director & Productora & Distribuidora \\
\hline \multirow[t]{3}{*}{1935} & Torpedero (Volldampf Voraus!, C. Froelich, 1934) & UFA & $\begin{array}{l}\text { Cinematográfica } \\
\text { Terra }\end{array}$ \\
\hline & Juana de Arco (Das Mädchen Johanna, G. Ucicky, 1935) & UFA & $\begin{array}{l}\text { Cinematográfica } \\
\text { Terra }\end{array}$ \\
\hline & El viejo Rey (Der alte und der junge König, H. Steinhoff, 1935) & Tobis & $\begin{array}{l}\text { Cinematográfica } \\
\text { Terra }\end{array}$ \\
\hline \multirow[t]{7}{*}{1936} & $\begin{array}{l}\text { Los jinetes del Africa colonial (Die Reiter von Deutsch Ostafri- } \\
k a, \text { H. Selpin, 1934) }\end{array}$ & $\begin{array}{l}\text { Terra } \\
\text { Film AG }\end{array}$ & Sud América \\
\hline & $\begin{array}{l}\text { Juana, el húsar negro (Schwartzer, Jäger Johanna, J. Meyer, } \\
\text { 1934) }\end{array}$ & $\begin{array}{l}\text { Terra } \\
\text { Film AG }\end{array}$ & Sud América \\
\hline & Rosas negras (Schwartze Rosen, P. Martin, 1935) & UFA & $\begin{array}{l}\text { Cinematográfica } \\
\text { Terra }\end{array}$ \\
\hline & $\begin{array}{l}\text { Guillermo Tell o la libertad de un pueblo (Wilhelm Tell, H. Paul, } \\
\text { 1934) }\end{array}$ & $\begin{array}{l}\text { Terra } \\
\text { Film AG }\end{array}$ & Sud América \\
\hline & $\begin{array}{l}\text { La vida privada de Luis XIV (Liselotte von der Pfalz, C. Frölich, } \\
\text { 1935) }\end{array}$ & Tobis & $\begin{array}{l}\text { Cinematográfica } \\
\text { Terra }\end{array}$ \\
\hline & Stradivarius (Stradivari, G. Von Bolváry, 1935) & $\begin{array}{l}\text { Boston } \\
\text { Films }\end{array}$ & Julio Joly \\
\hline & El secreto de la embajada (Die Insel, H. Steinhoff, 1934) & UFA & $\begin{array}{l}\text { Cinematográfica } \\
\text { Terra }\end{array}$ \\
\hline \multirow[t]{2}{*}{1937} & Tanques de guerra (Verräter, K. Ritter, 1936) & UFA & $\begin{array}{l}\text { Cinematográfica } \\
\text { Terra }\end{array}$ \\
\hline & Alarma en Pekin (Alarm in Peking, H. Selpin, 1937) & UFA & $\begin{array}{l}\text { Cinematográfica } \\
\text { Terra }\end{array}$ \\
\hline 1938 & Húsares de la muerte (Ritt in die Freiheit, K. Hartl, 1937) & UFA & $\begin{array}{l}\text { Cinematográfica } \\
\text { Terra }\end{array}$ \\
\hline
\end{tabular}




\begin{tabular}{|l|l|l|l|}
\hline 1941 & Caballeros en el aire (Pour le mérite, K. Ritter, 1938) & UFA & OCA \\
\hline 1942 & Submarinos rumbo al oeste (U-boote westwärts!, G. Tittau, 1941) & UFA & UFA \\
\hline
\end{tabular}

Fuente: elaboración propia en base al Heraldo del Cinematografista y La Nación.

El primero de estos estrenos fue Torpedero (1934), dirigida por Carl Frölich, producida por la UFA y distribuida por la Cinematográfica Terra, que tuvo su estreno el 14 de febrero en el cine Astor, continuando luego con funciones en las salas Select, Paramount, Crystal y Princesa. Esta película musical cuenta la historia de amor entre la hija de un constructor de barcos torpederos y el capitán de un barco rival. El principal atractivo del film es su despliegue de escenas con imponentes barcos - algunos de ellos militares - recreando maniobras navales, con carreras y ejercicios de tiro. La atmósfera del film se juega en una contraposición entre los avances técnicos del hombre y los peligros de la naturaleza, cuyas fuertes tormentas azotan a las naves. Tuvo escasa publicidad y permaneció durante tres semanas en cartelera.

El siguiente estreno de 1935 fue El viejo rey $y^{34}$, que tuvo su primera función el 16 de mayo. El film fue dirigido por Hans Steinhoff, quien había dirigido también, el año anterior, el film El flecha Quex (Hitlerjunge Quex) ${ }^{35}$, uno de los más abiertamente nazis. Tuvo producción de Tobis y contó con la distribución de Cinematográfica Terra. Luego de su estreno en el Ambassador, una sala del centro de la ciudad de Buenos Aires, pasó por otras salas: Palace, Astral y Paramount, todas ellas salas de estreno. Luego tuvo exhibiciones en los cines Hindú, Palais Royal, Callao y Florida, también en el centro de la ciudad. Ya en salas barriales, El viejo rey fue programada en los cines Argos, Regio y Etoile Palace, entre otros. Estuvo en total 16 semanas en cartelera ${ }^{36}$, lo que revela que fue un film bastante exitoso en cuanto a la atracción de espectadores. Este film retrata el heroísmo de grandes figuras masculinas que hicieron la historia de Alemania, participando así de una suerte de subgénero, los «Fridericus films», que contó con varias versiones durante la década de 1920 y 1930, que tuvieron gran popularidad en Alemania y que, según Sigfried Kracauer, respondían a una tendencia autoritaria en la mentalidad alemana, que parecía preferir un orden totalitario antes que el $\mathrm{caos}^{37}$. Según David Hull, «el guion de Thea von Harbou utilizaba los aspectos más brutales del conflicto entre padre e hijo, para enfatizar la necesidad de obedecer órdenes y otras virtudes adecuadas al régimen nazi $\rangle^{38}$. Resulta llamativo, sin embargo, que el tema haya sido de interés para el público porteño.

La película Juana de $\mathrm{ArCO}^{39}$, dirigida por Gustav Ucicky $^{40}$, se estrenó el 27 de setiembre de 1935, en el Cine Ideal, una sala de estreno ubicada en el centro de la ciudad. Luego fue exhibida también en los cines Capitol, Astral, Petit Splendid, Callao, Electric, Select Corrientes y Rose Marie, todos ubicados en el centro.
[34] N. del E. Estrena en España como El rey soldado.

[35] N. del E. Estrenada en España como Quex.

[36] Durante el año 1935 estuvo 13 semanas en cartelera, con varias funciones discontinuas desde su estreno en mayo hasta diciembre de ese año. Luego hubo una reposición del film en 1938, en salas barriales, con tres semanas de funciones.

[37] S. Kracauer, De Caligari a Hitler. Una historia psicológica del cine alemán (Buenos Aires, Paidós, 1985), p. 115.

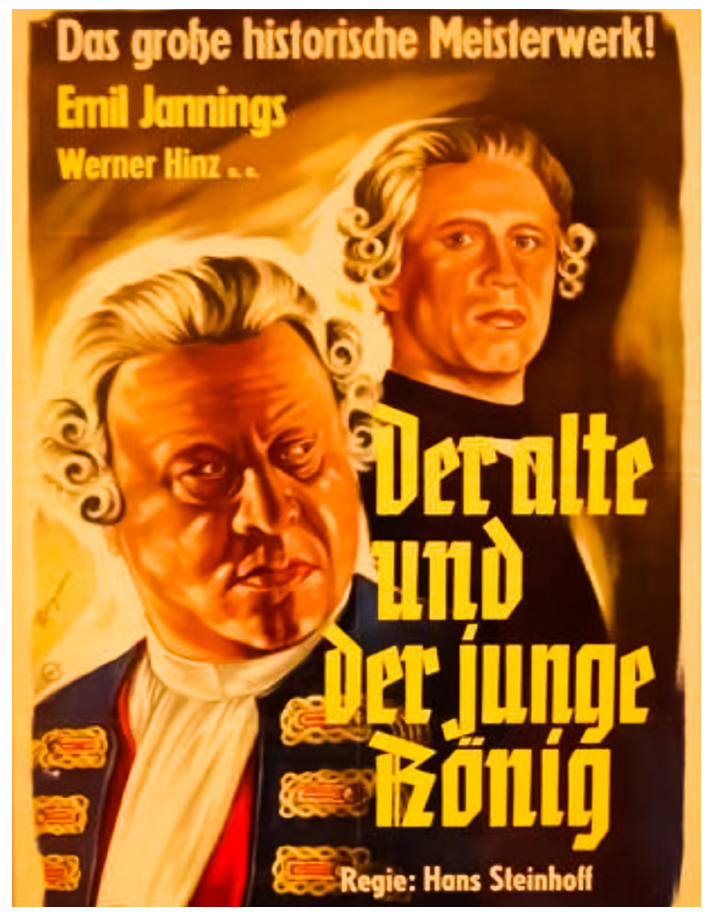

Afiche original de El viejo rey (Der Alte und der Junge König, H. Steinhoff, 1935). 
[38] David Hull, Film in the Third Reich. A Study of the German Cinema 1933-1945 (Londres, University of California Press, 1969), p. 82 (traducción propia).

[39] N. del E. Estrenada en España como Santa Juana de Arco.

[40] Más tarde sería el director de Heimkehr (1941), que no llegó a estrenarse en Argentina, uno de los films más virulentos en el retrato de la población polaca como violenta y agresiva contra la minoría alemana.

[41] Revista Criterio (n. ${ }^{\circ} 396$, 3/10/1935), p.105.

[42] J. Fox, Filming Women in the Third Reich (Oxford, Berg, 2000), p. 24 (traducción propia).

[43] Luego se repuso durante una semana, en febrero de 1937 , en la sala Belgrano, un cine de barrio.

[44] N. del E. Estrenado con el mismo título en España.

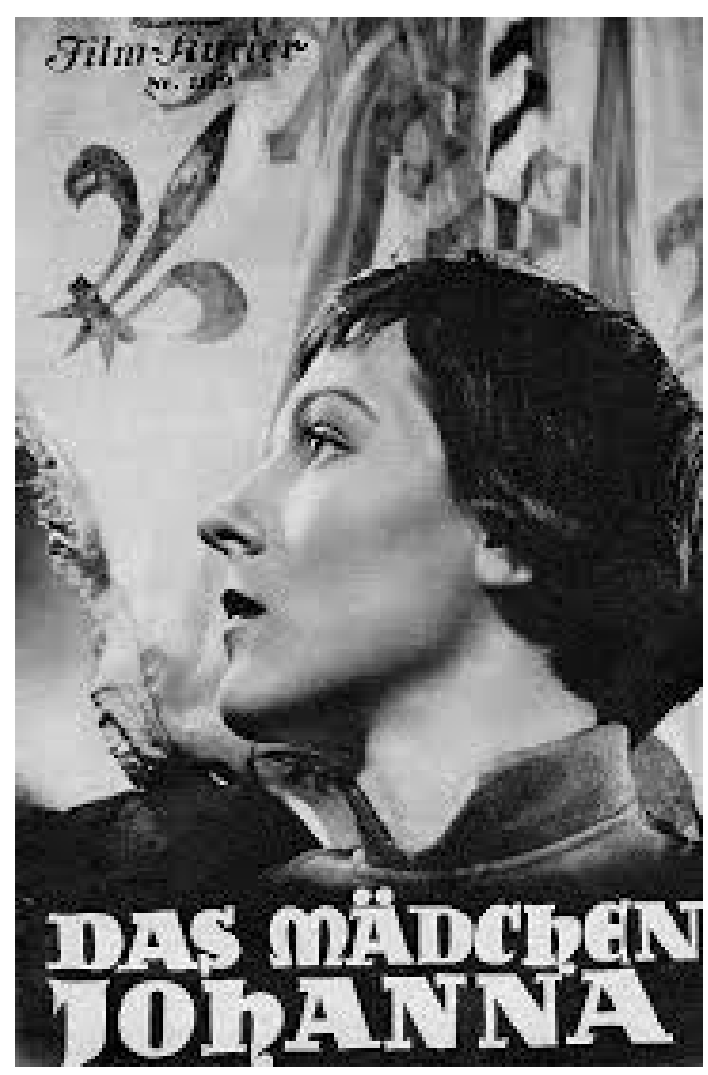

Publicidad gráfica en el diario La Nación, sobre el estreno de Juana de Arco (Das Mädchen Johanna, G. Ucicky, 1935).
Estuvo en total siete semanas en la cartelera porteña, lo que para la época representa una performance relativamente exitosa. Contó con publicidad gráfica en los diarios, acompañando su estreno, y recibió cierta atención por parte de la crítica, aunque no siempre favorable. La revista Criterio —órgano del catolicismo integral— publicó comentarios críticos firmados por monseñor Gustavo De Franceschi, quien señalaba: «es una producción tendenciosa, escrita y fotografiada con talento, y por eso mismo más eficaz en el servicio de su tendencia $\rangle^{41}$. Luego, en una extensa nota, se explaya con respecto a los motivos de reprobación de la película, que se refieren principalmente a la percepción de ataques contra la Iglesia. En cambio, los análisis académicos posteriores del cine de propaganda nazi encuentran que en Juana de Arco se construye una figura heroica, con la Juana protagonizada por Angela Salloker, en un personaje que podría considerarse «la primera encarnación femenina del Führer y una representación del heroísmo físico y espiritual ${ }^{42}$.

El año 1936 vio una importante cantidad de estrenos de películas de propaganda nazi. Fueron siete los títulos que luego aparecerían en las listas de películas prohibidas. El 8 de abril, en el cine Paramount, se estrenó Juana, el húsar negro, dirigida por Johannes Meyer, pero estuvo sólo una semana en cartel ${ }^{43}$. A continuación, el 22 de abril se estrenó Rosas negras ${ }^{44}$, dirigida por Paul Martin, en el Cine Monumental, una importante sala céntrica. Estuvo nueve semanas en cartelera, con funciones en simultáneo en varias salas de cine, todas en el centro: American, Callao, Paramount, Petit Splendid y el cine Once la ofrecieron en la semana del 10 de mayo de 1936. Luego continuó en salas barriales, a las que acudía un público más popular. En Rosas negras, un drama histórico, se presenta un triángulo amoroso en torno a una bailarina rusa (Lilian Harvey) que se encuentra en Finlandia, en el momento en que las autoridades alemanas son desalojadas de allí por el imperio de los zares ${ }^{45}$.

Esa misma semana, el 23 de abril de 1936, se estrenó Los jinetes del África colonial ${ }^{46}$, dirigida por Herbert Selpin, en el cine Paramount. Esta película transcurre durante la Primera Guerra Mundial, tematizando el conflicto entre los colonizadores británicos y alemanes en el África Occidental. Según la revista Criterio, el film se proponía «exaltar la fibra patriótica del pueblo alemán», aunque sin dejar mal parados a los ingleses; al respecto, David Welch señala que, durante los primeros años del nazismo, puede observarse en algunas películas la admiración hacia los ingleses, que expresaría cierta idea de solidaridad nórdica, como una suerte de internacionalismo racial ${ }^{47}$, aunque otros críticos como David Hull lo encuentran violentamente antibritánico ${ }^{48}$. Este título estuvo cuatro semanas en cartelera, pasando por los cines Renacimiento y Príncipe.

El 4 de junio de 1936 se estrena Guillermo Tell, dirigida por Heinz Paul. Basada en la obra de teatro de Friedrich Schiller, recrea la historia del héroe popular que combatía por la independencia de su pueblo y era 


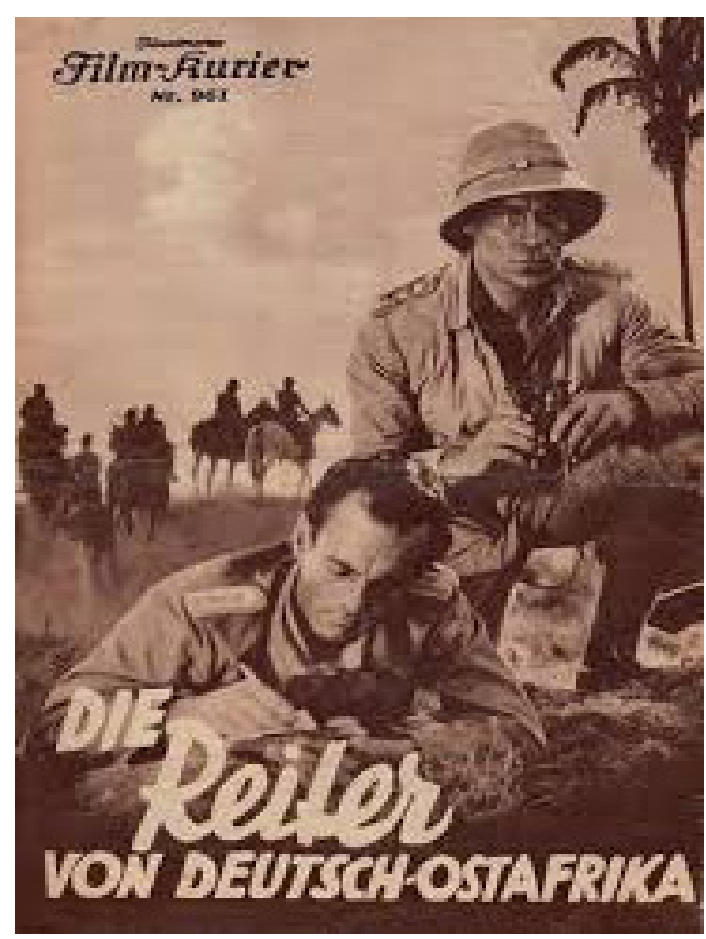

Afiche original de Los jinetes del África colonial (Die Reiter

von Deutsch Ostafrika, H. Selpin, 1934).

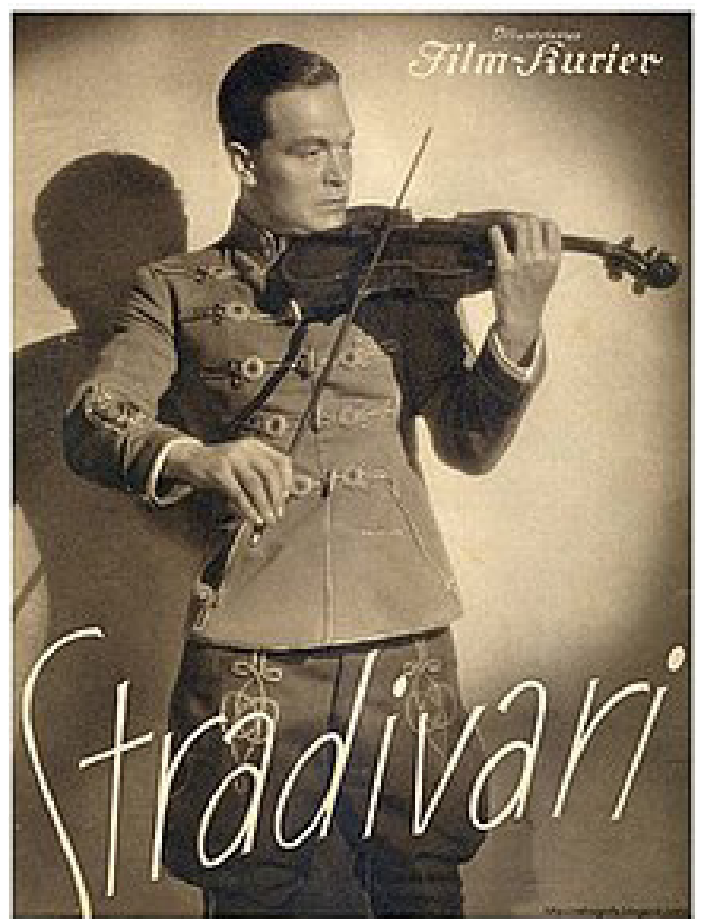

Afiche original de Stradivarius (Stradivari, G. Von Bolváry, 1935). famoso por su excelente puntería. Durante la filmación de esta película, Conrad Veidt fue detenido por expresar opiniones afines a los judíos ${ }^{49}$. El estreno fue en el cine Renacimiento. Contó con publicidad gráfica y una buena acogida por parte de la crítica en el diario La Nación, destacando la belleza de los paisajes naturales. Sin embargo, estuvo sólo una semana en cartelera.

El 23 de septiembre se estrenó Volga Volga, dirigida por Alexander Volkoff, en el cine Monumental, con distribución de Sud América. El film se basa en la leyenda popular en torno del personaje histórico de Stenka Rasin, un líder de los cosacos que se rebelaron contra el zarismo ruso. El film de Volkoff es un musical que, según la crítica de la época, se desluce en comparación con la película muda de 1928 del mismo título. El comentario del Heraldo indica que padece de una «deficiente dirección», que «la acción es muy lenta» y que «ha perdido fuerza dramática» ${ }^{50}$, pero no observa cuestiones ideológicas.

Algunas semanas más tarde, el 15 de octubre de 1936, se estrena Stradivarius en el cine Suipacha, una sala céntrica de Buenos Aires. Este film, dirigido por el prolífico director Géza von Bolváry, trata sobre un oficial húngaro que recibe un violín stradivarius — del cual se creía que traía mala suerte — y luego se ve separado de su prometida italiana al estallar la Primera Guerra Mundial. La película estuvo en cartelera durante diez semanas consecutivas, lo cual es indicador de un éxito considerable de espectadores, para los parámetros de la época. Fue programada por las salas Príncipe, Astral, Gaumont, Real Cine, National y Dante, ubicadas en su mayoría en el centro o en los barrios de Belgrano y Palermo. La crítica de espectáculos señaló la originalidad y lo emotivo del film, e indicó que «las escenas de guerra están en su
[45] Esta película fue también exhibida en Brasil, en la misma época, y como señala Luiz Nazario, para la crítica pasó desapercibida la metáfora por la cual «a través de una puesta en escena espectacular se asociaba a las cruzadas de liberación nacional con el movimiento nazi y se identificaba al zarismo con el comunismo, así como a Hitler se lo conectaba con los héroes de la independencia de otros países». Luis Nazario, «Nazi Film Politics in Brazil», en Roele Vande Winkel y David Welch (eds): Cinema and the Svastika. The International Expansion of the Third Reich (Londres, Palgrave Macmillan, 2007), p.89.

[46] N. del E. Estrenada en España como Héroes de África. ${ }^{\circ}-7$

[47] David Welch, Propaganda and the German Cinema. 1933-1945 (Nueva York, Tauris, 1983), p. 219.

[48] David Hull, Film in the Third Reich. A Study of the German Cinema 1933-1945, p.58. 
[49] T. Bergfelder, y C. Cargnelli, Destination London: German-speaking Emigres and British Cinema, 1925-1950 (Oxford, Berghan Books, 2008).

[50] Heraldo del Cinematografista $\left(\mathrm{n} .^{\circ} 274\right)$, p. 152.

[51] Heraldo del Cinematografista $\left(\mathrm{n} .^{\circ} 275\right)$, p. 1926.

[52] Publicidad gráfica en $\mathrm{La} \mathrm{Na-}$ ción (29/12/1936).

[53] Un discreto asunto: El secreto de la embajada» (La Nación, 29/12/1936).

[54] Varios meses luego de su estreno registramos una reposición en el cine Almagro, de carácter barrial, y en la misma sala, volvió a reponerse El secreto de la embajada en septiembre de 1938. Este tipo de práctica era bastante habitual en las salas de barrio de Buenos Aires, no así en las céntricas, consideradas salas de estreno.

[55] Klaus Kreimeier, The UFA Story. A History of Germany's Greatest Film Company, 19181945 (Berkeley, University of California Press, 1999), p. 245. mayoría recortadas de noticiarios o películas viejas», valorando que el ambiente de época estuviera «muy bien reproducido» ${ }^{51}$.

Ya sobre el final del año, se estrenó el 29 de diciembre de 1936 El secreto de la embajada en el Cine Ambassador. Este film protagonizado por Brigitte Helm y Willy Frost, dirigido por Hans Steinhoff, contó con importante publicidad gráfica en los diarios, que lo presentaron como un «film de intriga apasionante» ${ }^{52}$. El film trata sobre un conflicto que se desenvuelve en una embajada alemana, en la cual un aventurero intenta vender secretos de Estado para su beneficio, mientras que un agregado militar «decide patrióticamente afrontar el peligro» ${ }^{53}$. Era una producción de la UFA, de modo que fue distribuida por Cinematográfica Terra, y permaneció en cartelera durante nueve semanas ${ }^{54}$.

En 1937, si bien se mantiene un abundante flujo de películas alemanas (con 37 estrenos de ese origen), sólo dos títulos corresponden a películas que luego serán catalogadas como de propaganda. El 13 de mayo de ese año se estrena una de las películas que contó con cierto éxito en las salas porteñas: Tanques de guerra, al menos a juzgar por la permanencia durante 16 semanas en la cartelera porteña (cines Monumental, Cabildo, Petit Splendid, Renacimiento, Hindú). Contó con publicidad gráfica en la fecha de estreno y fue bien recibida por la crítica de espectáculos, que destacaba la modernidad de las imágenes. Las claves del éxito de este film parecen vincularse al interés del público por la temática bélica, al atractivo de las estrellas--la protagonista era Lida Baarova, quien fuera amante de Goebbels ${ }^{55}$ y luego disputada por Hollywood-y al despliegue técnico que se podía apreciar en las imágenes. En la prensa especializada, se señalaba que este film «ofrece el pretexto para mostrar la formidable estructuración industrial del mecanismo guerrero de una potencia moderna, que unifi-

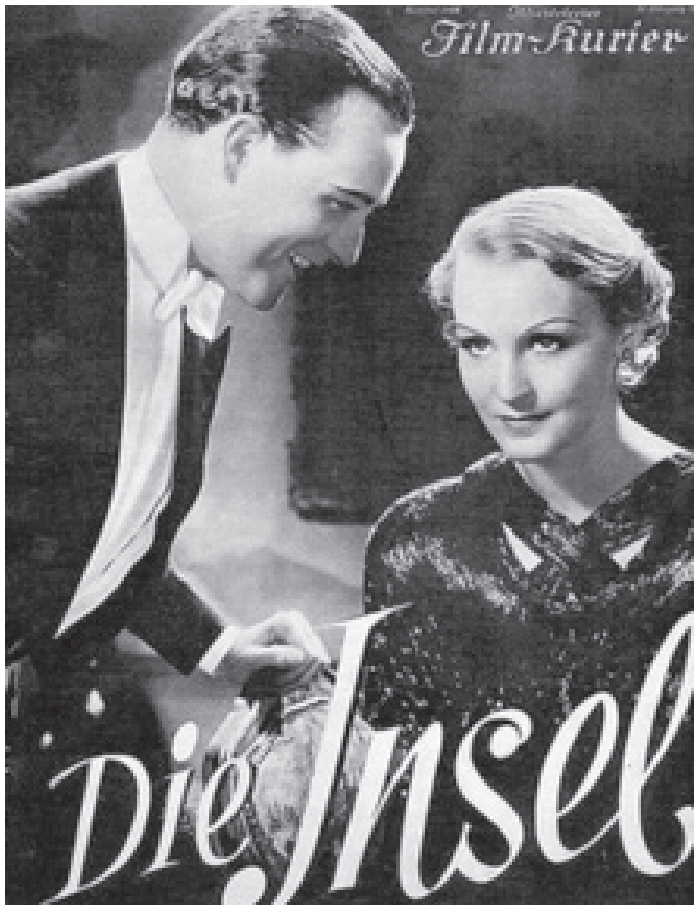

Publicidad gráfica en el diario La Nación, sobre el estreno de El secreto de la embajada (Die Insel, H. Steinhoff, 1934).

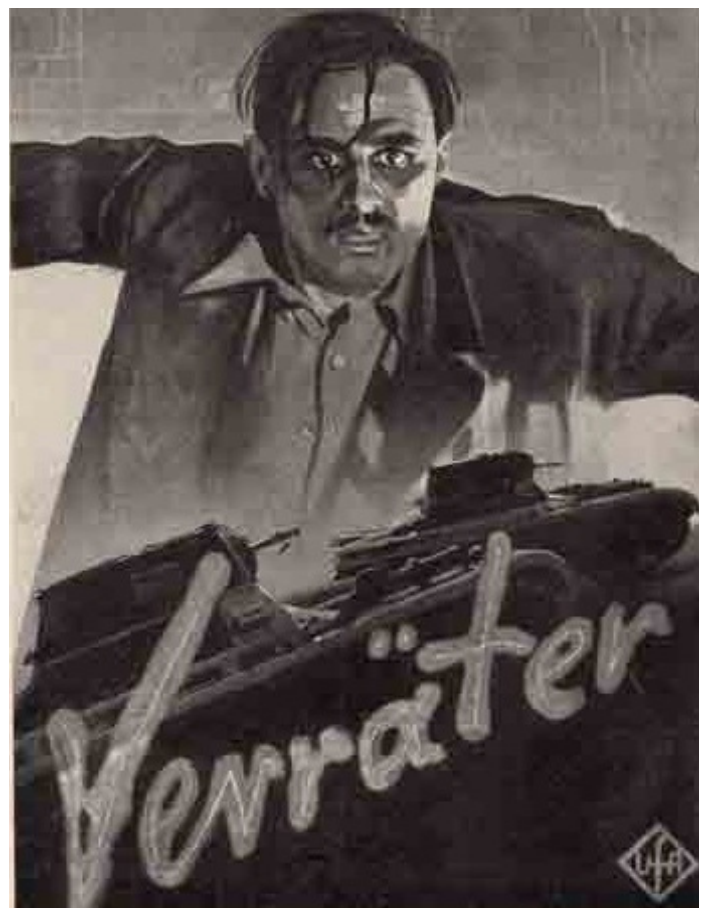

Póster de Tanques de guerra (Verräter, K. Ritter, 1936) en Alemania. 


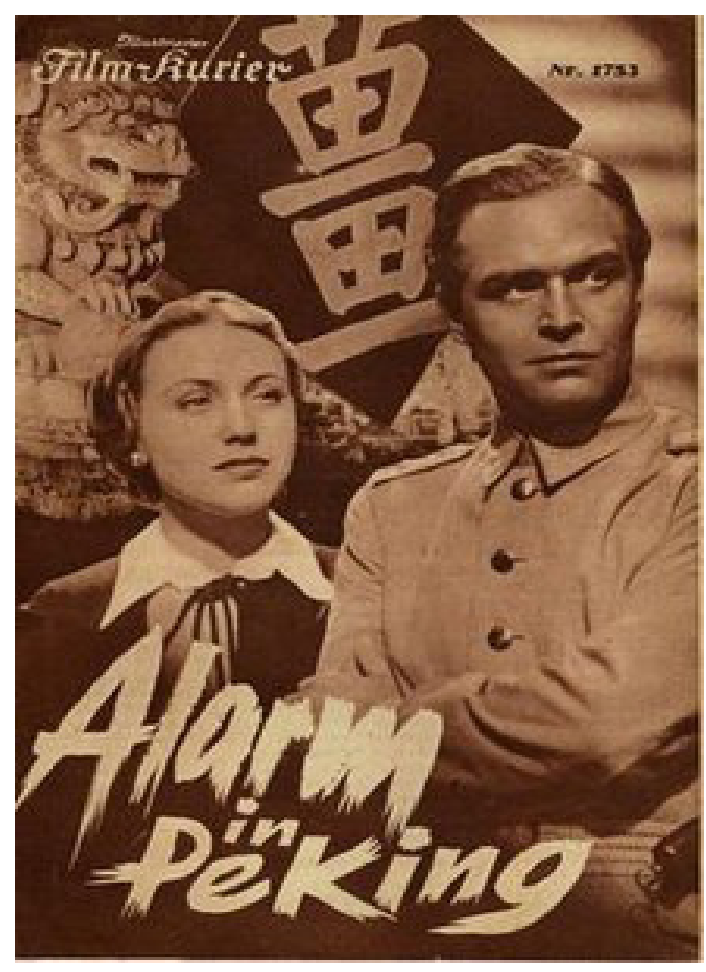

Póster de Alarma en Pekín (Alarm in Peking, H. Selpin, 1937) en Alemanial.
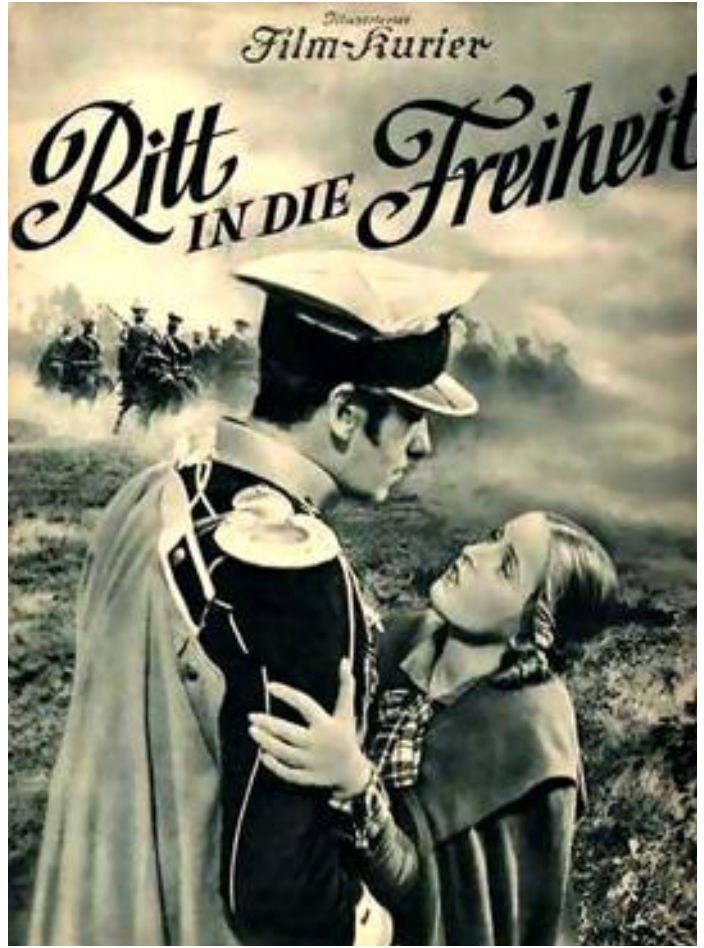

Póster alemán de Húsares de la muerte (Ritt in die Freiheit, $\mathrm{K}$. Hartl, 1937). ca, organiza y disciplina diversas especialidades encaminadas a dar tremenda eficacia a los descubrimientos técnicos puestos al servicio de la ciencia de la destrucción» ${ }^{56}$.

También en 1937, el jueves 30 de septiembre se estrenó Alarma en Pekín, con la actuación de Gustav Froelich, uno de los galanes del cine alemán de la época. Según la crítica del diario La Nación, el film evocaba la rebelión de los boxers y contaba con «movidas escenas bélicas». El comentario del Heraldo, señaló que era «de acción lenta» y que «no logra despertar mayor interés», indicando además que el film «exalta el heroísmo y la camaradería de los militares alemanes», por lo cual resultaría «más interesante a público alemán ${ }^{57}$, pero no se indica ninguna reserva con respecto al contenido político del mismo. Su estreno fue en el cine Monumental, pasando luego por las salas Callao, Petit Splendid, Select, Astoria e Hindú, con una permanencia total de 4 semanas en cartelera.

Durante 1938 se estrenaron en total 21 películas alemanas, de las cuales sólo una fue posteriormente considerada como de propaganda nazi: se trata de Húsares de la muerte $^{58}$, que se estrenó el 18 de enero de ese año, en el Ambassador. Con dirección de Karl Hartl, producida por UFA y distribuida por Cinematográfica Terra, contaba con la actuación de Willy Birgel y de Ursula Grabley. Como otras de las películas ya mencionadas, cuenta una historia de sublevación de un pueblo contra la opresión, en este caso se trata de levantamiento de 1830 contra el Imperio ruso en Polonia.

Es importante, en este punto, recordar que hacia fines del año 1938 se produce una escalada de violencia antisemita en Alemania, culminando con la Noche de los Cristales Rotos, durante los días 9 y 10 de noviembre de ese año ${ }^{59}$. La legislación
[56] Heraldo del Cinematografista $(27 / 05 / 1937)$.

[57] Heraldo del Cinematografista, n. ${ }^{\circ} 324$, p. 161.

[58] N. del E. Estrenada en España con el mismo título.

[59] Roderick Stackelberg, The Routledge Companion to Nazi Germany (Nueva York, Routledge, 2007), p. 156. 
[60] Francisco Pereda Castro, «Las cinematografías iberoamericanas en la encrucijada (19301942)» (Archivos de la Filmoteca, n. $\left.{ }^{\circ} 40,2002\right)$, p. 135.

[61] Alberto Manfredi, La industria cinematográfica en la Argentina. Disponible en: $<$ https://industriacinematograficaa. blogspot.com/2016/04/blog-post. html $\gg \gg(12 / 02 / 2020)$.

[62] «Confesiones de un espía nazi» (Argentina libre, 2/05/1940).

[63] María Eugenia Druetta, «En defensa de la neutralidad: el ejercicio de la diplomacia a través de la censura cinematográfica en Argentina, 1938-1940», presente en este monográfico (Secuencias. Revista de Historia del Cine, $\mathrm{n}^{\circ}$ 52, 2020), pp. 39-56

[64] N. del E. Estrenada en España como Forja de héroes. antisemita endurece las prohibiciones para la población judía en todos los niveles $\mathrm{y}$, en ese marco, se rompen las relaciones entre Cinematográfica Terra y la UFA: la empresa alemana decidió esta ruptura, debido a que no era ya aceptable para las leyes alemanas negociar con una distribuidora presidida por un empresario judío como Adolfo Zicovich-Wilson. De hecho, en ese momento, la actuación de los judíos estaba en Alemania prohibida en prácticamente todos los ramos.

Durante 1939 se estrenaron sólo 5 películas alemanas y en 1940 se estrenaron 6 títulos, en la mayoría de los casos distribuidos por Andes Film. Si bien ninguno de estos films estuvo incluido posteriormente en las listas de filmes de «propaganda nazi», algunos de ellos tenían un marcado carácter ideológico y fueron señalados como propagandísticos por los críticos, como es el caso de las películas de Leni Riefenstahl Olimpia (los dioses del estadio) (Olympia. Fest der Völker, 1938) y Juventud olímpica (Olympia. Fest der Schönheit, 1938), que se exhibieron en este período. También se continuaron programando los documentales de guerra de Alemania, con títulos como Espectacular desfile, Un año de guerra, Paracaidistas o Artillería, que eran distribuidos por la Organización Cinematográfica Argentina (OCA). Esta empresa estaba a cargo de Nicolas Di Fiori, propietario de varias salas de cine, quien recibía subsidios directos de la Embajada de Alemania en Argentina ${ }^{60}$.

A partir de 1940, las únicas empresas que continúan importando películas alemanas son la ya mentada OCA y la filial de la UFA en Buenos Aires. El boicot norteamericano contra las empresas que distribuyeran películas alemanas ya estaba en marcha, las listas negras hacían temer a los empresarios que dejarían de recibir las deseadas producciones de Hollywood y el cine alemán empezó a tener cada vez mayores dificultades para llegar a las pantallas. Sin embargo, el clima político en Buenos Aires no estaba aún del todo definido con respecto a la disputa y la prédica antifascista generó también reacciones contrarias ${ }^{61}$, como demuestra el episodio en torno de Confesiones de un espía nazi (Confessions of a Nazi Spy, Anatole Litvak, 1939). En mayo de 1940, la Comisión Asesora de Control Cinematográfico decidió impedir la proyección de esta película norteamericana de la Warner Bros, por considerar que era ofensiva para Alemania; esta decisión despertó críticas de los sectores antifascistas ${ }^{62}$ y luego, cuando el intendente municipal de Buenos Aires Arturo Goyeneche vetó la prohibición, permitieron el estreno, se desataron críticas de los sectores pro-alemanes, neutralistas y del catolicismo integral.

En octubre de 1940 volvió a producirse un conflicto, en este caso, en torno de la censura de la película El gran dictador (The Great Dictator, 1940), de Charles Chaplin, cuya exhibición fue prohibida en Buenos Aires a partir de los reclamos tanto de la Embajada de Alemania como de la de Italia, por la burla que se hacía sobre las figuras de Adolf Hitler y de Benito Mussolini ${ }^{63}$. De nuevo, hubo quejas por parte de la prensa liberal — como el diario Crítica o La Prensa - que, en abierta oposición a la medida, decidieron cubrir con detalles el estreno de esta película en Nueva York, o bien viajaron a la vecina Montevideo para asistir al film y reseñarlo; mientras que los sectores cercanos al Eje o que sostenían posiciones neutrales, aprobaban la decisión. Durante el año 1941 se estrenaron sólo 6 películas alemanas (y varios cortometrajes documentales), distribuidas en todos los casos por la propia UFA o por la ya mencionada OCA. Entre ellas, el 16 de enero de 1941 se exhibió en el cine Alvear el film Caballeros en el aire ${ }^{64}$, dirigido por Karl Ritter, considerado como propaganda nazi, puesto que retrata las aventuras de un grupo de pilotos alemanes durante la Primera Guerra Mundial hasta el ascenso del nazismo, en un tono que exalta el nacionalismo 
y el heroismo, incluyendo un llamado abierto al rearme alemán. Era considerado por los críticos como un Zeitfilm, es decir, una película militarista, que debía mostrar tanques, aviones y tropas en el frente, retratando el heroísmo y la actitud positiva de los alemanes. El propio Hitler asistió al estreno del film en Alemania, declarando que lo consideraba «el mejor film de historia contemporánea hasta la fecha» ${ }^{65}$. La película se cierra con la proclamación de Hitler a los pueblos, el 16 de marzo de 1935, en la cual anunció el reinicio de la conscripción militar, rompiendo así el Tratado de Versalles. Si bien la crítica de La Nación no encuentra nada problemático en el film, la reseña que se publicó en el Heraldo sí indica que «por su definida intención política, es sólo apta para público simpatizante con el régimen nazi» ${ }^{66}$.

Por último, ya en 1942, se estrenaron sólo cuatro películas alemanas, una de las cuales tenía un claro carácter propagandístico: Submarinos rumbo al oeste (U-boote westwärts!, G. Tittau, 1941), dirigido por Günther Rittau.

Era una película propagandística de temática bélica, que mostraba a la marina nazi (Kriegsmarine) en

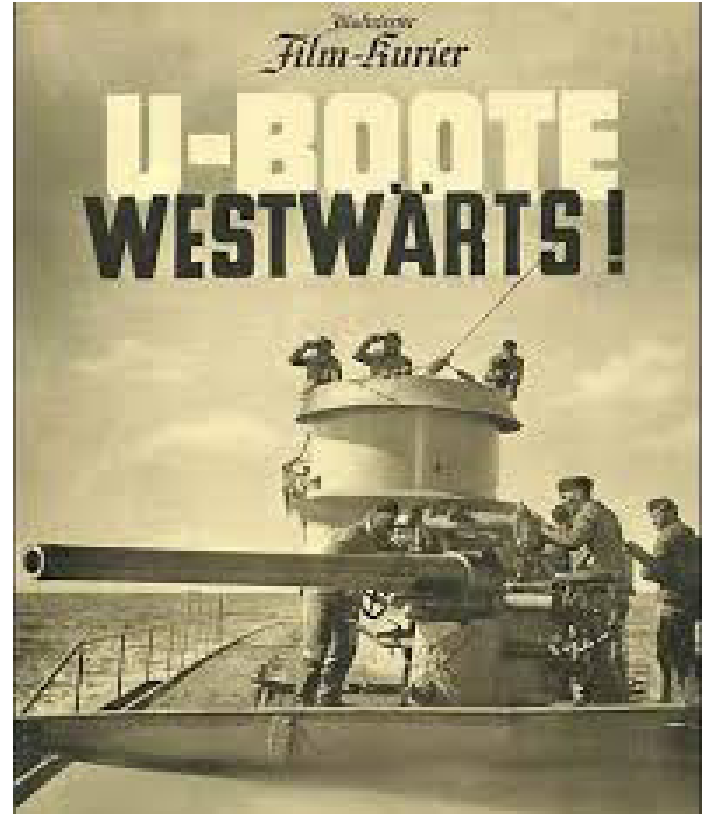

Póster alemán de Submarinos rumbo al Oeste (U-boote westwärts!, G. Tittau, 1941). acción. En el film, se presenta a la tripulación de un submarino alemán, que se dirige a una misión en la que deberá abordar un barco holandés, pero luego será atacado con torpedos por una nave británica. Esta película fue distribuida directamente por la oficina local de la UFA, que para entonces era la única que importaba películas alemanas, y cuyas actuaciones en breve serían prohibidas. Se exhibió en el cine Astoria, con una permanencia en cartelera de 5 semanas (fue una de las películas que estuvo durante más tiempo en pantalla ese año), y fue repuesto luego en 1943, en la misma sala. El cine Astoria y el cine Hindú, en este período en el que estaba muy limitada la posibilidad de distribuir cine alemán en Argentina, programaron varias reposiciones de películas alemanas estrenadas durante los años previos.

\section{Conclusiones}

La diplomacia cultural alemana en la Argentina de entreguerras se caracterizó por concentrar esfuerzos en áreas de alcance masivo en las sociedades de la época, radio, prensa gráfica y cine, principalmente. Esto se debía en parte a que la coyuntura política local era considerada un escenario propicio para la intervención cultural e ideológica nazi. Asimismo, la clausura de la participación política que sufrió la sociedad argentina en la década del 30 repercutió en la desmovilización generalizada y, aun cuando un sector si se vio efectivamente conmovido por la agenda internacional, esta movilización parcial se produjo sólo de manera asociada a intereses políticos locales. En este sentido, el antifascismo argentino previo a la guerra se superpuso también con una derecha local nacionalista, antisemita y anticomunista que defendía al régimen alemán.

En este contexto, la importación de películas germano-parlantes en el país sudamericano fue fluida hasta la intervención norteamericana para cercenar los esfuerzos

[65] Citado en David Welch, Propaganda and the German Cinema. 1933-1945, p. 162.

[66] Heraldo del Cinematografista, n. ${ }^{\circ} 494$ (enero de 1941). 
[67] Jeffrey Richards, Visions of Yesterday (Londres, Routledge, 2016).

[68] Sabine Hake, Popular Cinema of the Third Reich, p. 145.

[69] S. Brockmann, A Critical History of German Film (Nueva York, Camden House, 2010), p. 145 .

[70] Para ello sería necesario utilizar medidas estadísticas que contemplen no sólo la cantidad de funciones y la cantidad de días o semanas que permaneció cada film en cartelera, sino también el tamaño y la importancia relativa de los cines en los que fue exhibida, como se indica en John Sedgewick, «Measuring Film Popularity», en Michael Ross, Manfred Grauer y Bernd Freisleben, (eds). Digital Tools in Media Studies (Nueva York, Columbia University Press, 2009). propagandísticos del régimen nazi en América Latina. Entre 1935 y 1939 se estrenaron en total 109 películas alemanas en Argentina. A partir de entonces se observa una clara merma de la llegada del cine de este origen, y los pocos estrenos que se mantienen, se explican casi exclusivamente por la acción directa de la Embajada de Alemania, a través de su alianza con OCA o a través de la oficina local de la UFA. En cuanto a la orientación de las películas alemanas que se importaron, es importante recordar que el cine alemán del período nazi presenta una enorme heterogeneidad temática y de géneros. Entre las películas que se estrenaron en Buenos Aires, encontramos representantes de los tres grandes tipos temáticos de films que propone Jeffrey Richards $^{67}$ : a) películas que se centran en un líder — que suele reflejar al Führer-y sus seguidores, entre las cuales podríamos clasificar a El viejo rey, Juana de Arco y Guillermo Tell; b) películas que representan disciplina, camaradería y el vínculo con la madre patria, como El secreto de la embajada, Húsares de la muerte y Alarma en Pekin; c) y los que construyen una imagen negativa sobre los judíos y los ingleses, como Submarinos rumbo al oeste. Resulta interesante destacar que no hubo, entre los filmes estrenados en Buenos Aires, casos de películas abiertamente antisemitas, lo cual pudo deberse a la resistencia de los representantes locales de las firmas que importaban las cintas, que en muchos casos eran de origen judío.

En cuanto a las películas más propagandísticas, de las cuales registramos 15 títulos que se programaron en salas de cine de Buenos Aires, notamos que en varios casos resultaron exitosas en su convocatoria de espectadores, a juzgar por la extensa permanencia en cartelera que lograron. Notamos que en la mayor parte de los casos la crítica de espectáculos no registró aspectos problemáticos en las películas, limitándose las más de las veces a realizar un comentario técnico sobre las mismas. En este sentido, nuestros hallazgos coinciden con lo que señala Sabine Hake respecto de la «recepción apolítica» ${ }^{68}$ que tuvo el cine alemán en los Estados Unidos: los críticos parecen, en la mayoría de los casos, observar sólo los aspectos técnicos y artísticos de los filmes. También constatamos que había un público interesado en estas películas, o al menos en algunas de ellas, puesto que en varios casos permanecieron durante meses en la cartelera.

Debido a las dificultades que supone una primera aproximación al tema, nuestra investigación se enfrentó a la escasez de datos o publicaciones previas sobre la circulación de cine alemán en general y nazi en particular en América Latina. Por ese motivo decidimos limitar el registro exhaustivo a los títulos que figuraban en alguna de las listas de películas consideradas «reservadas». Como señala Stephen Brockmann, la cuestión de qué constituye propaganda política en el cine alemán de la época ha recibido diferentes respuestas y aún continúa despertando debates ${ }^{69}$. No obstante ello, la literatura especializada indica que muchas veces la frontera entre las películas de propaganda y el cine de entretenimiento alemán son borrosas, y que sería necesario proponer una revisión más extensa y detallada.

En definitiva, consideramos que nuestro trabajo abre nuevos interrogantes y vías de investigación. De este modo, por ejemplo, una tarea pendiente que esperamos desarrollar en el futuro próximo es analizar la popularidad de las películas de propaganda nazi en Argentina ${ }^{70}$, y resta aún analizar la distribución y exhibición de cine alemán en Argentina, más allá de las películas de las listas. Asimismo, sería deseable también contar con trabajos que avancen en un análisis temático, formal y estético de estos films, así como de los procesos de recepción en América Latina. 


\section{FUENTES}

Colección de Materiales de la Izquierda Antifascista, Microfilmado y conservado en el Centro de Documentación e Investigación de la Cultura de Izquierdas (CeDInCI), Buenos Aires, Argentina.

«Entrevista a Luis Vainikoff», por Valeria Galván y Michal Zourek (Buenos Aires, junio 2016).

Colección revista Criterio, depositada en Fundación Criterio, Tucumán 1438, Buenos Aires, Argentina, 1935-1942.

Colección revista Excelsior, depositada en la Biblioteca de la Escuela Nacional de Experimentación y Realización Cinematográfica (ENERC), Buenos Aires, Argentina, 1935-1942.

Colección Heraldo del Cinematografista, depositada en la Biblioteca de la Escuela Nacional de Experimentación y Realización Cinematográfica (ENERC), Buenos Aires, Argentina, 1935-1942.

Diario La Nación, Hemeroteca de la Biblioteca del Congreso de la Nación Argentina, 1935-1942.

\section{BIBLIOGRAFÍA}

Bergfelder, T. y Cargnelli, C. Destination London: German-speaking Emigres and British Cinema, 1925-1950 (Oxford, Berghahn Books, 2008).

Bisso, Andrés, Acción Argentina: un antifascismo nacional en tiempos de guerra mundial (Buenos Aires, Prometeo, 2005).

Brockmann, S., A Critical History of German Film (Nueva York, Camden House, 2010).

Buchrucker, Cristián, Nacionalismo y Peronismo (1930-1955). La Argentina en la crisis ideológica mundial (Villa Ballester, Sudamericana, 1999).

De Privitellio, Luciano, «La política bajo el signo de la crisis», en Alejandro Cattaruzza, Crisis económica, avance del Estado e incertidumbre política 19301943: Nueva Historia Argentina. Vol. 7 (Buenos Aires, Sudamericana, 2014).

Díez Puertas, Emeterio. Cine español y geopolítica fascista. España y sus relaciones cinematográficas con la Argentina (1939-1943) (Madrid, Síntesis, 2019).

Druetta, María Eugenia, «En defensa de la neutralidad: el ejercicio de la diplomacia a través de la censura cinematográfica en Argentina, 1938-1940» (Secuencias. Revista de Historia del Cine, n. $^{\circ}$ 52, 2020), pp. 39-56

ECHEVERRÍA, Olga, «La derecha nacionalista. Decepciones políticas e influjos culturales», en Leandro Losada (comp.), Política y vida pública. Argentina (1930-1943) (Buenos Aires, Imago Mundi, 2017), pp. 61-64.

-, «Las derechas de Argentina y Uruguay en tiempos de nazi fascismos: radicalización, redefiniciones e influencias» (Oficina do historiador, n. ${ }^{\circ}$ 9, 1, 6-2016), pp.151-170. Disponible en: <http:/hdl.handle.net/11336/26643>.

Finchelstein, Federico, Fascismo, liturgia e imaginario: el mito del General Uriburu y la Argentina nacionalista (Buenos Aires, Fondo de Cultura Económica, 2002).

Fox, Jo. Filming Women in the Third Reich (Oxford, Berg, 2000).

Friedmann, Germán, «El discurso nacionalsocialista en la Argentina frente a la “infiltración nazi”» (Prohistoria, vol. 32, 2019).

Friedmann, Germán, Alemanes antinazis en la Argentina (Buenos Aires, Siglo 
Veintiuno Editores Argentina, 2010).

FuHRMAnN, Wolfgang, «Sueños en blanco y negro: la expansión de la UFA en Brasil y América Latina», (Secuencias. Revista de Historia del Cine, n. ${ }^{\circ}$ 52, 2020), pp. 57-76

Garncarz, Joseph, Begeisterte Zuschauer: Die Macht des Kinopublikums in der NS-Diktatur (Köln, Halem, 2020).

HaKe, Sabine, Popular Cinema of the Third Reich (Austin, University of Texas Press, 2001).

Halperín Donghi, Tulio, La Argentina y la tormenta del mundo (Buenos Aires, Siglo XXI, 2003).

Hull, David. Film in the Third Reich. A Study of the German Cinema 1933-1945 (Londres, University of California Press, 1969).

ILARI, Virgilio, «Verbotene Filme I Kriegsfilme del Terzo Reich» (Conference paper, mayo de 2015). Disponible en: < https:/www.researchgate.net/publication/ 274989203_Verbotene_Filme_I_Kriegsfilme_del_Terzo_Reich>.

Kelson, John F. y Short, Kenneth (eds.), Catalogue of Forbidden German Feature and Short Film Productions: Held in Zonal Film Archives of Film Section, In formation Services Division, Control Commission for Germany (Trowbridge, Flicks Books, 1996).

KLICH, Ignacio, «La contratación de nazis y colaboracionistas por la Fuerza Aérea Argentina» (Ciclos en la historia, la economía y la sociedad, Año X, Vol. X, n. ${ }^{\circ} 19$, 2000), pp. 177-216.

KraCauer. S., De Caligari a Hitler. Una historia psicológica del cine alemán (Buenos Aires, Paidós, 1985).

Kreimeier, Klaus. The UFA Story. A History of Germany's Greatest Film Company, 1918-1945 (Berkeley, University of California Press, 1999).

Kriger, Clara, "Gestión estatal en el ámbito de la cinematografía argentina (1933-1943)» (Anuario del Centro de Estdios Históricos Prof. Carlos S. A. Segreti, año 10, n. $\left.^{\circ} 10,2010\right)$.

Losada, Leandro (comp.), Política y vida pública. Argentina (1930-1943) (Buenos Aires, Imago Mundi, 2017).

Martínez Mazzola, Ricardo, «El Partido Socialista en los años treinta», en Leandro Losada (comp.), Política y vida pública. Argentina (1930-1943) (Buenos Aires, Imago Mundi, 2017).

Nazario, Luis, «Nazi Film Politics in Brazil», en Roele Vande Winkel y David Welch (eds.), Cinema and the Svastika. The International Expansion of the Third Reich (Londres, Palgrave Macmillan, 2007).

Paranaguá, Paulo Antonio, «América Latina busca su imagen», Historia General del Cine. Vol. X, (Madrid, Cátedra, 1996).

PAsolini, Ricardo, «Comunismo y cultura política comunista: el momento antifascista»,en Leandro Losada (comp.), Política y vida pública. Argentina (1930-1943) (Buenos Aires, Imago Mundi, 2017).

-, Los marxistas liberales. Antifascismo y cultura comunista en la Argentina del siglo XX (Buenos Aires, Sudamericana, 2013).

Pereda Castro, Francisco, «Las cinematografías iberoamericanas en la encrucijada (1930-1942)» (Archivos de la Filmoteca, n. $\left.^{\circ} 40,2002\right)$.

Prutsch, Ursula, Creating Good Neighbors? Die Kultur- und Wirtschaftspolitik der USA in Lateinamerika, 1940-1946 (Stuttgart, Steiner, 2008).

Rapoport, Mario, Musacchio, Andrés y Converse, Christel, «Las inversiones 
alemanas en Argentina entre 1933 y 1945: ¿base material de la expansión de los nazis?» (Iberoamericana, VI, 21, 2006).

Rentschler, Eric., The Ministry of Illusion. Nazi Cinema and its Afterlife (Boston, Harvard University Press, 1996).

Richards, Jeffrey, Visions of Yesterday (Londres, Routledge, 2016).

Sedgewick, John, «Measuring Film Popularity», en Michael Ross, Manfred Grauer y Bernd Freisleben (eds)., Digital Tools in Media Studies (Nueva York, Columbia University Press, 2009).

StaCKelberg, Roderick, The Routledge Companion to Nazi Germany (Nueva York, Routledge, 2007).

TATo, María Inés, «El ejemplo alemán. La prensa nacionalista y el Tercer Reich» (Revista Escuela de Historia, 1.6, 2007).

TAтo, María Inés y Romero, Luis Alberto, «La prensa periódica argentina y el régimen nazi», en I. KLICH (comp.), Sobre nazis y nazismo en la cultura argentina (Gaithesburg, Ediciones Hispamerica, 2002).

VANDE Winkel, Ry Welch, D., Cinema and the Swastika: The International Expansion of Third Reich Cinema (Basingstoke [etc.], Palgrave Macmillan, 2007).

Welch, David, Propaganda and the German Cinema. 1933-1945 (Nueva York, Tauris, 1983).

Witte y Karsten, «Film im Nationalsozialismus», en Wolfgang JACOBSON, Welten Kees y Hans Helmut Prinzler (eds.), Geschichte des deutschen Films (Stuttgart, Springer-Verlag, 2016).

Zanca, José, Cristianos antifascistas. Conflictos en la cultura católica argentina (Buenos Aires, Siglo XXI, 2013).

Recibido: 8 de junio de 2020.

Aceptado para revisión por pares: 24 de junio de 2020.

Aceptado para publicación: 16 de enero de 2021. 